Article

\title{
Product Design Supporting Improved Water, Sanitation, and Energy Services Delivery in Low-Income Settings
}

\author{
Taylor Sharpe ${ }^{1}$, Christian Muragijimana ${ }^{2}$ and Evan Thomas ${ }^{1, *(1)}$ \\ 1 Mortenson Center in Global Engineering, University of Colorado Boulder, Boulder, CO 80303, USA; \\ taylor.sharpe@colorado.edu \\ 2 School of Public Health, University of Nairobi, Nairobi 00100, Kenya; christian.muragijimana@sweetsensors.com \\ * Correspondence: evan.thomas@colorado.edu
}

Received: 21 September 2019; Accepted: 25 November 2019; Published: 27 November 2019

\begin{abstract}
Several approaches have been proposed in the literature supporting product design applied in low-income settings. These approaches have typically focused on individual- and household-level beneficiaries, with an emphasis on participatory, human-centered co-design methods. In this paper, we present a design approach that is, in contrast, focused on supporting providers of improved water, sanitation, and energy services. We establish requirements for design in these contexts, especially addressing design iteration. We describe sets of feedback systems between designers and various sources of expert knowledge, codifying roles of design stakeholders in this context. We demonstrate these principles across three case studies: a sanitation service monitoring technology in Kenya; a water flowmeter technology in Kenya; and a water storage monitoring technology in Sierra Leone.
\end{abstract}

Keywords: service design; service delivery; global health; water and sanitation; IOT

\section{Introduction}

Recent product design literature has presented approaches for product design applied in low-income settings. Sometimes referred to as "design for the bottom of the pyramid", "design for the developing world" [1], or "social sector human-centered design" [2], these approaches often frame the end-beneficiary a customer, even when they are not, in fact, retail consumers. The intent is to treat the beneficiaries as engaged co-designers to develop products that "support development of resource-poor individuals or enhance their capabilities" [3]. These approaches attempt to redress the reality that the majority of the world's engineering effort flows towards product design for the most affluent fraction of the global population.

In this paper, we present a design approach that is, in contrast, designed to support professionals working to improve water, sanitation, and energy service delivery. This paper describes elements of a design theory for product development to enable improved services, with a focus on clear definitions of stakeholder feedback roles throughout the design process. The common goal of design methodologies for global development is poverty reduction and a positive health impact. However, our methodology emphasizes improving and sustaining basic services rather than household-level consumer product design. This approach prioritizes partnership with governments, utilities, and implementing agencies as the relevant stakeholders in this design process.

This approach embraces some components of the emerging consensus around beneficiary co-design, while also maintaining a more traditional relationship between the target product user and the designer. 
We use iterative design, rapid prototyping, and small-batch manufacturing techniques popularized by the aerospace, automotive, and biomedical industries [4], modular product design approaches [5], remote design approaches enabled by advanced computer-aided design (CAD) and communication technologies, and customer feedback systems akin to the human-centered design approach [6].

\section{Context}

Barriers to achieving the United Nations Sustainable Development Goals (SDGs) for access to clean drinking water, safe sanitation, and affordable, clean energy are formidable. Over half of the world's population lacks access to safely managed sanitation, a third of the global population lacks access to safe drinking water [7], while roughly 3 billion people burn biomass for their daily energy needs, increasing exposure to air pollution [8]. Limitations of existing program models for global development interventions must be met with a renewed focus on feedback, accountability, and sustained service delivery [9].

Our team has leveraged the Internet of Things (IoT) to connect infrastructure and public health interventions to data platforms, with the goal of improving the effectiveness and sustainability of these interventions. We focus on the design and manufacture of internet-connected products that can interface with existing infrastructure. We have designed products to improve levels of service delivery and operations and maintenance practices for water infrastructure [10], to inform stakeholders regarding the use of sanitation technologies [11], to understand actual consumer behaviors around new technologies [12], to measure health impacts of interventions [10], to establish new methods for higher-efficiency sanitation service delivery [13], and to examine consumer behaviors in the face of climate change [14]. By providing products that can help service providers and public health practitioners fill in critical gaps in available data, these efforts have worked towards a more transparent and measurable field global engineering [15]. This paper presents an approach for the design of connected products to improve basic services delivery.

\section{Design for Improved Services Approach}

Some elements of design in low-resource settings, especially for products focused on basic needs like clean water and sanitation, differ from standard industrial design processes. Infrastructure is often under-serviced, difficult to reach, and lacks documentation [16]; staff are often constrained by other responsibilities or by other institutional structures; funding or purchasing can be highly constrained [17]; access to design and construction resources can be difficult [16]; and some products, especially those used in basic or applied research settings, might only be produced once and used for only one project, making traditional product scaling models inappropriate.

In most cases, our approach envisions professional representatives of service providers as end-users. In the context of this paper, these users are referred to as "partners" and are co-designers of the product, which is intended to solve problems they have identified. The problem is most commonly related to a gap in knowledge or feedback, as previously described.

In some other cases, the end-user is simultaneously the subject of monitoring and the recipient of the data-for example, a feedback display offering a family real-time feedback on their indoor air quality. In all cases, lines of communication and feedback between product designers and other stakeholders must be made explicit and must inform one another. Often, market pressures that define the quality, accessibility, or marketability of new products look very different in the global engineering context. The network of stakeholders can also be complicated, containing many moving parts that must be accounted for. Because data is only actionable if a complex systems approach is adopted by implementers [18], iteration is a critical component to designing in complex systems [19]. We therefore identify iterative processes between each design phase. 
Despite an apparent emerging consensus around the inappropriateness of remote design [20], we have demonstrated some benefits to collaboration at a distance, enabled through the use of cloud-based computer-aided design (CAD) software and persistent online communication. Strengthening the feedback between in-house and in-field rapid prototyping processes is vital in our context. In addition, by embracing non-traditional manufacturing technologies, design iteration can continue far into the product lifecycle. Up-to-date modifications can be made to the product based on field and stakeholder feedback. State-of-the-art software tools can be used to improve communication between every stakeholder: the engineer, the field technician, the manufacturer, and the implementing partner.

Some literature acknowledges the "expert" status of stakeholders beyond the expertise of the product designer [3,21]. Design for high-quality service delivery requires an acknowledgment of the roles of experts in product design, realities in the field, and the needs and capacity of partners. At different phases of the design cycle, these roles take varying levels of primacy. By clearly defining the roles of these stakeholders in a design process and by acknowledging the expertise of each, a structured design approach can developed.

Figure 1 outlines our proposed design process by which feedback from partners and field collaborators can inform the product design effort by helping the designer iterate, while Table 1 expands on our definition of stakeholder roles during each phase of product development.

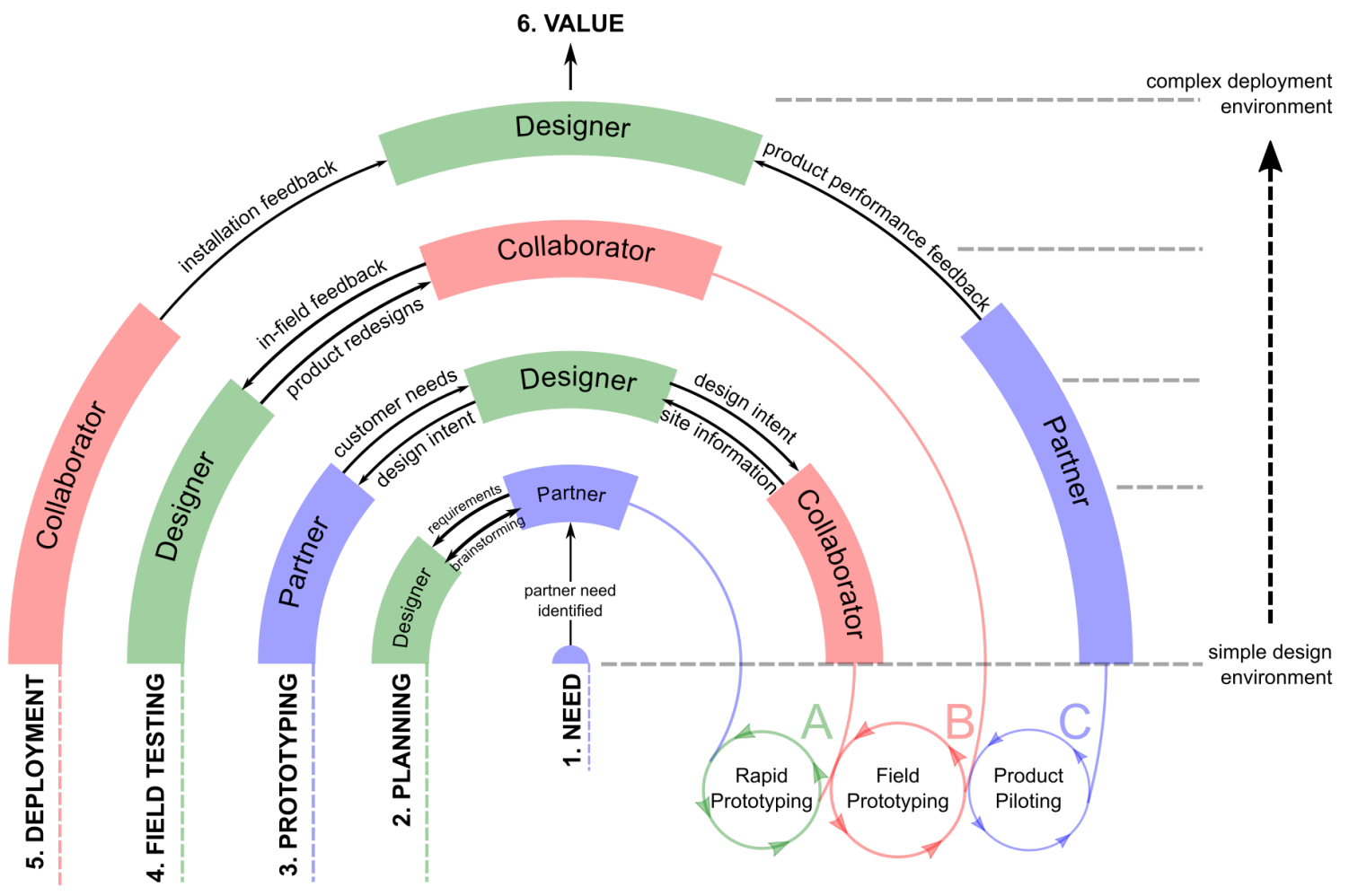

Figure 1. Proposed product design for service delivery approach, including the roles and feedback between each design stakeholder (Design Phases 1-5). Iterative product design processes occur between product development phases (Iteration Phases A-C). 
Table 1. Design Phases.

\begin{tabular}{llll}
\hline Phase & Roles & Complexity & Iteration \\
\hline 1 & $\begin{array}{l}\text { Partner identifies gap in service delivery. } \\
\text { Negotiation process finds an idealized product that serves the partner's } \\
\text { needs and aligns with the designer's capabilities. }\end{array}$ & Low & - \\
3 & $\begin{array}{l}\text { Designer prototypes internally, aligning product with idealized vision } \\
\text { from Phase 2. }\end{array}$ & Low & Brainstorming \\
4 & $\begin{array}{l}\text { Collaborator physically tests prototypes in the field, providing } \\
\text { feedback. Partner provides feedback regarding alignment with their } \\
\text { customers' needs. }\end{array}$ & Medium & $\begin{array}{l}\text { Prototyping } \\
\text { Field Prototyping }\end{array}$ \\
& $\begin{array}{l}\text { Field deployment occurs on a pilot project scale. Designer is provided } \\
\text { with customer feedback from partner and installation feedback from } \\
\text { collaborator. } \\
\text { Service delivery impacts, product adoption, and value are measured in } \\
\text { order to demonstrate the product's performance. }\end{array}$ & High & Pilot Project \\
6 & & & - \\
\hline
\end{tabular}

Project Phase 1: Need

Service providers are aware of issues regarding the efficiency of their services, maintenance of their infrastructure, and communication with their customers. Projects in this space result from identification of gaps in information or feedback systems that can alleviate these issues or from the recognition of an opportunity to improve service delivery.

Project Phase 2: Planning

The planning phase focuses heavily on the needs of the partner and how the capabilities of the designer can help meet these needs. The goal is to produce a vision for how a product may function to address the identified service need.

Project Phase 3: Prototyping

Initial prototyping occurs within the rapid prototyping environment. The designer balances internal capabilities with inputs from the partner regarding desired capabilities and inputs from the collaborator regarding broad site information. The goal is to produce a minimum viable product for field testing as rapidly as possible. Simulations of the field environment may be used to improve the resilience of the product but should not replace field testing and the other rounds of prototyping it triggers.

An integrative rapid prototyping process, informed by new data from the field, will often continue through many design iterations. Each new round of field testing kicks off a new round of rapid prototyping (Figure 1, A).

\section{Project Phase 4: Field testing}

The result of the initial prototyping phase of product development is put in the hands of the collaborator, who begins to test the product in situ. Generally this phase will occur in a small number of pilot locations representative of the systems managed by the partner. This phase is heavily focused on feedback from the collaborator. In most cases, the designer must iteratively respond to field information, providing multiple redesigns in virtual and physical form. We call this field prototyping (Figure 1, B).

Project Phase 5: Deployment

Following any necessary rounds of field prototyping, a pilot project is often very useful before beginning full-scale deployment, providing critical feedback before manufacturing begins (Figure 1, C). Once the product has fulfilled the desired capabilities of the partner, the collaborator has confirmed that the 
product aligns with field conditions, and the designer has done all due diligence to create a high-quality, safe, and scalable product, manufacturing and deployment can begin. Deployment should be accompanied by continued feedback from partners and collaborators to improve the odds of high demonstrated value.

Project Phase 6: Demonstration

Most products designed for this context fail to demonstrate enough value to go to scale or to measurably impact livelihoods.

Value can be demonstrated through improved efficiency or outcomes; improved operations and maintenance capabilities; access to useful knowledge that was previously locked away; or improved lines of communication with customers. Demonstration of a product's utility usually comes down to changes in important metrics-for example, a decrease in the total number of hours an average pump in a fleet spends offline.

\section{Roles of Stakeholders in a Service Delivery Design Setting}

\subsection{Roles of Designers and Collaborators}

The taxonomy introduced in this paper is an attempt to codify the roles of three main stakeholders (individuals or organizations) in the design of products to improve service delivery in low-income, resource-constrained settings. The partner might be a government office, a utility, or a utility's employee. The designer might be an engineering company or a non-profit, a design team within some larger organization, or a single mechanical or industrial engineer. A collaborator might be a team of enumerators on staff, a community health worker, or a field staff member.

Designers

Designers lead the process of product design. In order for a product to be well designed for reliability and scalability, the expertise of the designer must be multifaceted:

- Designers must be experts in product design in order to contribute successfully to projects that alleviate poverty or improve global health. This may seem self-evident, but others have noted the prominent role of students and engineers untrained for the low-income context in low-resource product design [20].

- Designers must have a deep knowledge of material science in order to properly envision and design an appropriate product. Inappropriate material choices can result in premature product failure or suboptimal behavior.

- Designers must have deep knowledge of manufacturing processes in order to enable any degree of scale or even a successful pilot project. Designing products without manufacturing knowledge will result in suboptimal parts.

- Designers hold responsibility for the sustainability and safety of their designs [21]. It is therefore necessary for the head designer or design team to have knowledge about product lifecycles and the impacts of design decisions.

- Designers must approach design problems from a high-level, systems view. Innumerable product failures in development engineering projects can be tracked back to a singleminded focus on the product itself, failing to take the context fully into account [22]. Designers should be part of a larger team that includes experts in program evaluation in order to assess the impacts of products and programs [23].

- Designers must have knowledge of the context in which their products will be used [21,22]. Some of this knowledge can come second-hand from design collaborators and partners, but it is highly 
advantageous and often critical for the designer to also visit the areas in which his or her products will be used.

- In our context, the designer must also serve as a mediator between the partner and the field design collaborator. The designer is effectively the project manager in terms of product design.

Field Design Collaborators

Field design collaborators are the eyes and ears of the designers. They are experts in the local environment in which products will be deployed, gaining this expertise both by immersion and by active measurement efforts, for example, by thoroughly documenting an infrastructure site prior to installation of instrumentation. Efficiently and rapidly producing a product requires simultaneous access to rapid prototyping tools and environmental data specific to the product's context. Combining these roles is often impossible in our context due to constraints on manufacturing capabilities [24]. Balancing these constraints requires a mediator between the designer, focused on hardware prototyping, and the environment in which installation and use will occur.

Although we share a broad concern about the inability of designers to solve problems outside of their known context, reliable local or embedded design collaborators can reduce these risks while allowing design engineers to contribute globally. Feedback from the field provides critical elements to the rapid prototyping process but is often unavailable in direct co-location to the intended market. Remote design between collaborators working virtually has been critically examined [25], supporting the use of communication technologies as platforms with similar outcomes to face-to-face activities. Other research has indicated good design results with good flow of information between a design expert and an environmental expert, a role functionally similar to the design collaborator described here [26]. A special focus on the relationships between different types of local and dispersed experts improves project success [27].

\subsection{Roles of Partners}

In our case, partners are water, sanitation, and energy service providers and supporting implementing agencies. In general, our products seek to enable service providers to inform their actions with access to more or to better data. The most important question in such a context is whether the data is actionable, requiring well-designed feedback systems in addition to the technology and data generated by the project [28].

Partners are experts in the context of their role as a government, utility, or business providing resource access to their customers or constituents. They also are experts in the ways in which their funding, data, or regulatory structures fall short in successfully providing these resources.

Partners often lack access to data that could improve their efficiency, operations and maintenance schemes, systems-level approaches, customer feedback systems. Monitoring tools have a significant role to play in helping service providers meet the goals of the SDGs regarding access to safe drinking water, allowing service providers to respond to the needs of their customers [29]. Identification of the data that could improve the strength of these systems falls heavily on the shoulders of these service providers. The role of communication with the customer is clearly within the partner's wheelhouse, although at times the product or service provided by our design team might serve to improve this. An example is given in one of the case studies in a following section. 


\subsection{Roles of Markets}

This category refers to new information to inform product design that is gathered prior to the product entering the market. In some cases, this may be during a pilot project, but it more often refers to updates to design information gained between deployments or projects.

The literature describes numerical approaches to dealing with uncertainties by minimizing risks while maximizing the versatility of products in an iterative optimization process [30], an approach that acknowledges the high level of uncertainty that exists in the developing market context. Others have attempted to deal with market uncertainties in low-income settings by taking a "hybrid design" approach in which incremental product improvements are offered following a small initial investment by the customer [5].

The design approach described in this paper requires agile design and production strategies since it assumes changes in design requirements as more information becomes available.

\section{Case Studies}

In this section, we describe three case studies to demonstrate some of the design approaches we take in the service delivery context, in pursuit of stronger systems to support human health in resource-constrained environments: a sanitation service monitoring technology in Kenya; a water flowmeter technology in Kenya; and a water storage monitoring technology in Sierra Leone. In each case, we embrace an idea similar to hybrid design, in which a reliable universal gateway can be used to rapidly respond to changing or emerging partner needs through the development of new accessories, like the examples shown in Figure 2. A single gateway can help partners collect a wide variety of data.
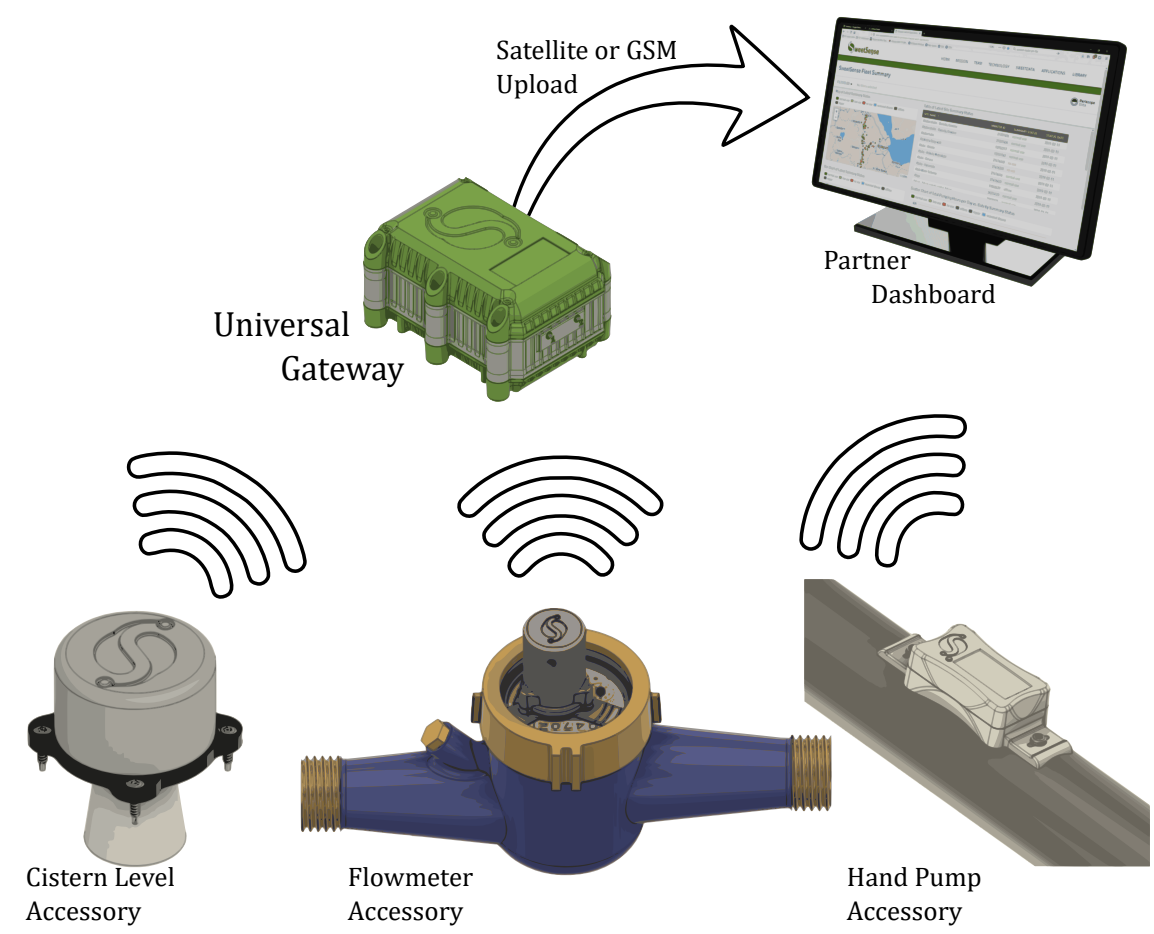

Figure 2. A hub-and-spoke design maximizes system reliability by maintaining an existing gateway design while responding to new needs by developing new accessories. 


\subsection{Sanitation Service Monitoring}

The passive latrine use monitor (PLUM) was an early example of how IoT data could inform the impact of sanitation services on health [31]. Passive infrared (PIR) sensors can collect occupancy data based on movement within a latrine. A PLUM logs this data locally or transmits it to a server for analysis. Our team continued this work by implementing cellular telemetry capabilities, with the research goal of quantifying latrine use to help evaluate public health interventions [11]. In this case study, we highlight the importance of feedback between design stakeholders and the iterative relationships between design phases.

Sanergy Inc. is a social enterprise in Nairobi, Kenya. Sanergy works to improve access to sanitation technologies in unplanned settlements by franchising their Fresh Life branded latrines to local franchisees, Fresh Life Operators (FLOs). FLOs charge a fee for each latrine use, simultaneously developing a business model and improving access to safe sanitation. FLOs are expected to maintain the cleanliness of the latrine. Unlike a pit latrine, Fresh Life toilets contain liquid and solid waste bins designed for easy transportation. Sanergy staff empty these bins on a daily or nearly daily basis, and the waste is converted into fertilizer and feed stock.

Based on the perceived inefficiency of emptying every latrine every day, we sought to use cellular transmitted sensor data to give waste collectors real-time data about fill levels in a group of pilot latrines. The initial research question was whether access to fill data could improve waste collectors' efficiency by prioritizing only latrines that had a chance of filling before the next collection cycle. During the planning phase (Figure 1, Design Phase 2), we identified a set of possible sensors that could provide useful data to Sanergy.

An initial pilot phase saw the co-deployment of three sensor types in three latrines with the goal of zeroing in on one sensor. Following rapid prototyping (Figure 1, Iteration Phase A) with a scale model in the lab, a weight sensor, liquid bin pressure sensor, and PIR occupancy sensor were evaluated in the field (Figure 1,4). Low correlations between the liquid fill level and the solid fill level were observed, eliminating the pressure transducer option. The weight sensor was accurate but expensive to produce and difficult to install. A good correlation was observed between PIR data and weight data in the three pilot latrines, so the PIR was selected as a basis for a new product design. At this point, the product design cycle was essentially reset back to the rapid prototyping phase (Figure 1, A).

Sanergy operations staff were interested in gathering data about waste collector routes, including the time of collection, the specific collector, and information about the status of the latrine. Waste collectors confirmed that SMS would be an ideal way to receive information from the PLUM sensors, rather than an online dashboard or some other form of feedback. Sanergy field officers facilitated conversations with FLOs to obtain their desired product capabilities.

A small team of enumerators were hired during the project to collect data, install sensors, and provide feedback to the design team. These collaborators co-designed a field weighing system to collect liquid and solid container data and moved with waste collectors on their routes. These data were used to calibrate, ground-truth, and evaluate fill estimates from sensors in both the pilot and deployment phases of the project.

During the pilot phase of the project, multiple instances of a FLO attempting to communicate with Sanergy to solve maintenance issues in their latrine were observed. Conversations with FLOs identified this communication gap as important to proper operation of Sanergy's network of latrines. Based on these conversations, a new desired capability emerged for the product: a mechanism that could leverage the sensor network to improve lines of communication between FLOs and Sanergy maintenance teams, creating a rapid line of communication between end-users and our partners. 
Based on these various sources of feedback during prototyping, a field prototyping process (Figure 1, B) was undertaken in order to augment the existing capabilities of the PLUM. The goal was to integrate feedback from two levels of partners on the project:

- Enable near-real-time tracking of waste collector visits to latrines and their decisions to service or not service the latrine;

- Incorporate a system for quick communication between FLOs in the project and Sanergy's maintenance staff.

To facilitate future capabilities and upgrades, the original PLUM was designed using a modular manufacturing approach. The main enclosure is injection-molded polycarbonate with a molded silicone gasket and has been extensively tested in the field. The PIR housing external to the enclosure is industrially 3D printed with marine-grade potting material used to weatherize external electronics. By modifying the external housing, additional capabilities can be unlocked without compromising internal functionality. As shown in Figure 3, an off-the-shelf radio frequency identification (RFID) reader was incorporated into the enclosure along with tamper-resistant mounting provisions for use with a bracket designed for the Sanergy latrines.

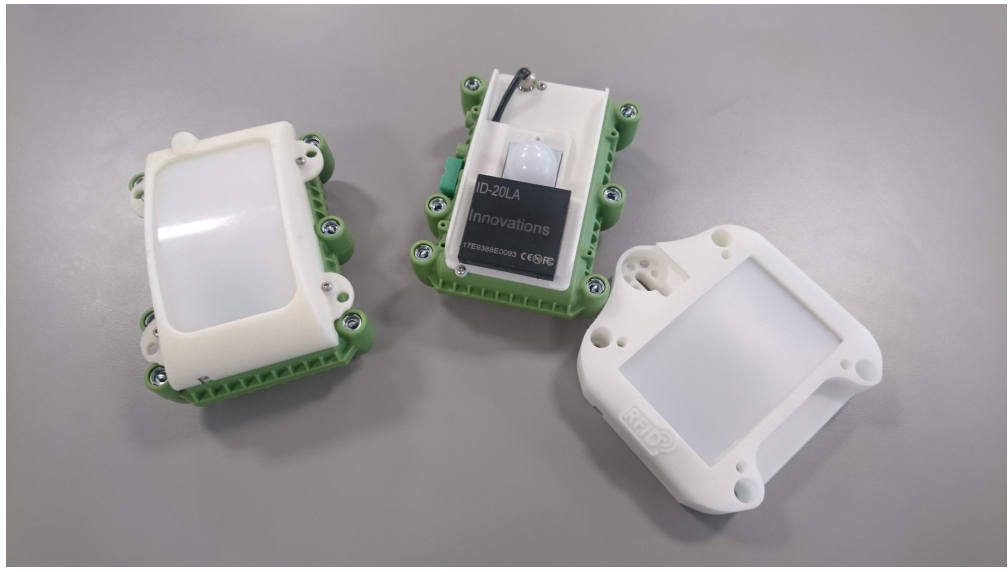

Figure 3. The original passive latrine use monitor (PLUM) design (left) was modified with a laser-cut custom bracket and industrial 3D-printed enclosure (right) to incorporate a RFID reader and tamper-resistant mounting system.

Product piloting (Figure 1, C) followed the field prototyping phase. A total of 40 sensors were installed in latrines along a high-use route. The installation team was made up of the enumerators described as collaborators above and a Sanergy field manager. A machine learning system was used to automatically generate SMS messages informing waste collectors when they could safely skip servicing a latrine without risk of overflow. Adherence to these generated schedules was tracked through RFID swipes from waste collectors.

RFID swipes from FLOs automatically generated salesforce work orders, integrating into Sanergy's existing work order system, decreasing the number of steps and the complexity of communication required to register a maintenance issue, and ensuring that maintenance staff followed up on it.

This project did not go to scale in Sanergy's fleet of 700+ latrines. The goal was to explore possible service route optimization strategies. Following a quasi-experimental study described elsewhere [13], Sanergy found that the most useful element of the design was the RFID system to improve communication between FLOs and Sanergy staff. Sanergy is now piloting a project that would more directly incorporate this capability into their service delivery model. 


\subsection{Water Flow Monitoring}

Our team has installed hundreds of satellite- and cellular-connected sensors that monitor current draw from pumps on water infrastructure in Kenya and Ethiopia. An initial cellular capability was identified by our field design collaborator and partners as insufficient given the poor network coverage. The resultant satellite-connected instruments are now deployed across the region. The data collected are pump runtimes, which can be used to estimate water extraction [14,32].

In some cases, higher-accuracy water volume data could enable stronger regulatory environments in order to drive down the prevalence of non-revenue water (NRW). NRW is defined as water resources lost before reaching paying customers and is particularly acute in developing markets. The World Bank estimates that in developing countries, NRW surpasses 4 billion dollars annually, with 45 million cubic meters lost daily through water leakage in the distribution networks-enough to serve nearly 200 million people. An additional 30 million cubic meters are delivered every day to customers but are not invoiced because of pilferage, employee corruption, and poor metering. This directly affects the capacity of utilities in emerging markets to become financially viable and fund necessary expansions of service, especially for the poor [33].

While installing borehole sensors, staff members began to report on the prevalence of existing flowmeter infrastructure during site visits. Recent literature has pointed to existing infrastructure as useful beyond its intended purpose [34], and our own research has used sensors primarily intended for improved service delivery to also examine more academic elements of water resource management [14]. While these meters were originally installed to be read manually, they present an opportunity to begin to quantify actual flow data to reduce misreading and the labor burden through IoT retrofit, without requiring expensive new infrastructure installations. This, coupled with prior requests for high-resolution flow data from a number of partners, established a need for the project (Figure 1, 1).

Photographs of a number of flow meters photographed by SweetSense Inc. (Denver, CO) staff in the field were compiled to examine the range of existing, functional mechanical flowmeters that might be available for IoT retrofit (Figure 1, 2).

Two representative flowmeters were purchased, one in Kenya and the other in the United States, similar to those observed in operation in northern Kenya. The two meters differed in dimension but worked using the same operating principles. A rapid prototyping process (Figure 1, A) was used to develop a sensor that could interface with either of these meters. This process was undertaken as rapidly as possible, with the foreknowledge that field requirements would not match the conditions in the lab. An initial prototype serves as a point of initial comparison for the collaborator, in this case a staff engineer for SweetSense Inc.

A minimum viable prototype was shipped to our collaborator in Kenya along with a gateway that was programmed to gather data from the prototype. A number of new design constraints were generated by this field-testing process, (Figure 1,4):

- Varying geometries: It was found that the first prototype could not fit some flowmeter faceplates at existing installations. Flowdometer geometries would need to be modified more completely to accommodate varying flowmeter designs.

- Solar resource variations: Many existing flowmeters were housed inside opaque, tamper-resistant boxes. This removed the solar resource available to the accessory. A battery would need to replace the solar panel as the Flowdometer's source of energy.

- Installation feedback: Collaborator feedback indicated that a better system for ensuring that installation had been carried out properly was required. A feedback LED would need to be incorporated. 
Following field testing, a field prototyping cycle was completed (Figure 1, B). The next version of the product incorporated an internal battery and a more modifiable outer plate to accommodate a wider range of existing infrastructure.

The new prototype was evaluated during a second round of field testing (Figure 1,4). The redesigned Flowdometer was compatible with a greater range of flowmeters but was still too large for some common models. The orientation of the battery would need to be changed to decrease the profile of the device. In addition, collaborators discovered that some existing mechanical flowmeters had provisions for a reed switch incorporated in the field. A way to connect existing reed switches to the prototype would be ideal.

By rapidly responding to feedback from collaborators and by rapidly producing new product designs that can be tested in the field, we can quickly adjust to the local context. The V3.0 prototype is now undergoing field testing. Based on collaborator feedback, the orientation of the accessory now allows for installation on smaller faceplates; the solar panel has been replaced by a battery; an indicator LED has been included; and external reed switch hookup provisions have been added. Depending on further testing and field feedback, another round of field prototyping may be undertaken before deployment as part of a pilot project.

\subsection{Stored Water Monitoring}

In partnership with the Guma Valley Water Company in Freetown, Sierra Leone, we are undertaking a pilot project exploring the use of distributed sensor networks to track drinking water resources in near-real-time. Water service delivery in Freetown, Sierra Leone, is currently sporadic and difficult to manage, partially because a distributed network of drinking water cisterns are filled and emptied unpredictably. Cistern filling is accomplished with water trucking, making efficiency a high priority. A sensor accessory that can update a dashboard with the current fill level of these cisterns could help the Guma Valley Water Company prioritize water trucking to cisterns with low existing water levels, giving a birds-eye view of water use, supply, and resource requirements in the city.

Figure 1, 2, Planning: The customer and the designers outlined a set of desired capabilities to address the lack of timely cistern fill data. The goal of measuring existing water levels inside cisterns, along with estimates of daily use and fill-testing capabilities, were compared against the capabilities of possible solutions including flowmeters and pressure transducers.

Figure 1, 1, Internal Prototyping: As shown in Figure 4, an off-the-shelf weatherized distance sensor (MaxBotix, Brainerd, MN, USA) was interfaced with a custom circuit board to take and transmit distance readings. The electrical components are mounted inside an off-the-shelf enclosure modified with 3-axis mill engraving and precision cuts for o-rings. The prototype printed circuit board (PCB) was routed on a 3-axis desktop mill. Autodesk (San Francisco, CA, USA) Fusion 360 and EAGLE software packages maintain an associative connection with the manufacturing capabilities in the lab.

In-house PCB prototyping dramatically decreases the time required for the first phase of the design cycle by cutting out the weeks-long waiting period for professional PCB manufacturing. After initial testing has validated the PCB design, sample PCBs can be ordered with a high chance of success. Combining 3D printing with desktop milling provides a low-cost solution to rapidly iterating and testing two-sided circuit boards.

An in-house cistern simulator, with an 8 foot water column that can be filled and emptied to random levels with a microcontroller, was used to validate the output of the sensor. 


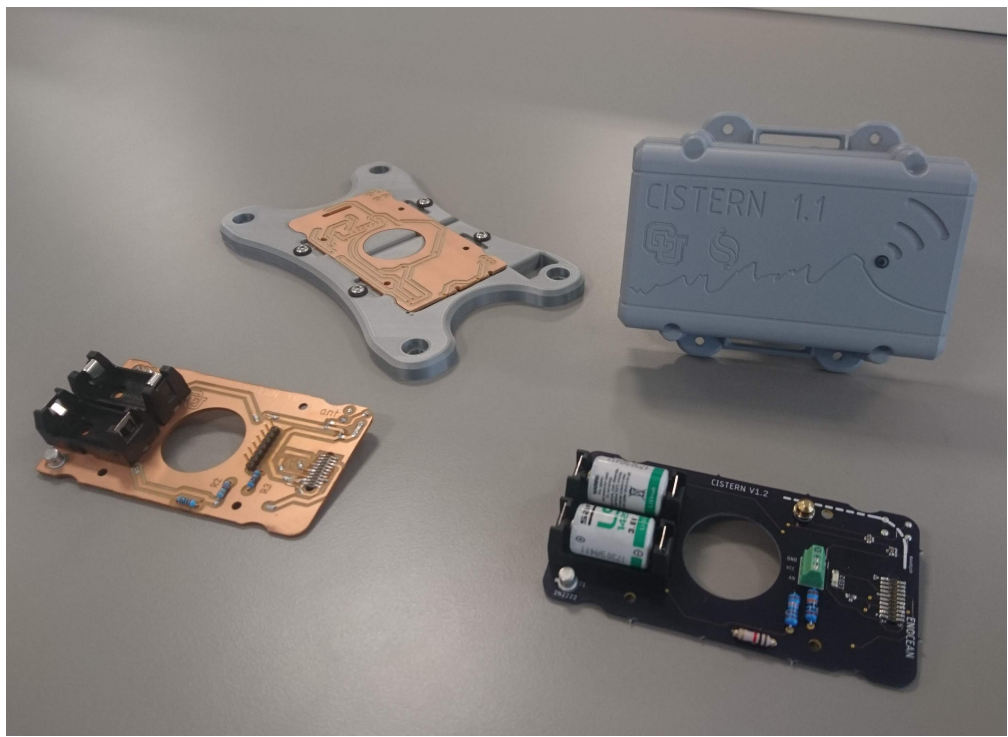

Figure 4. The initial rapid prototyping phase of sensor development is accelerated by milling printed circuit board (PCB) prototypes using an associative 3D-printed fixture to enable rapid, high precision two-sided PCB milling.

Collaborator feedback provided site information to define the mechanical requirements for the product (Figure 1,3). Local Sierra Leone collaborators provided photographs and dimensions of potential field installation infrastructure (Figure 5). Outdoor cisterns of 10,000 L capacity and $2000 \mathrm{~L}$ indoor kiosk cisterns were identified for prototype installation. By combining collaborator-provided photographs with manufacturer specs, the design team developed 3D models of the planned installations, virtually testing mechanical interfaces between the existing infrastructure and the product.

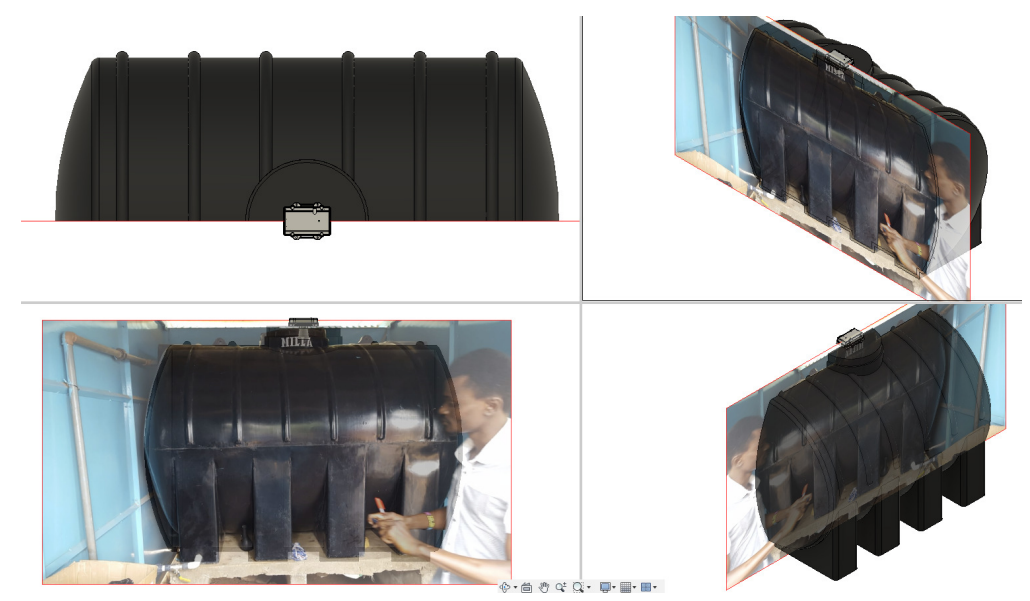

Figure 5. Collaborator feedback is crucial to effectively using remote design to improve early product prototypes. In this case, collaborators provided a few photographs and hand measurements to allow the design team to develop a virtual kiosk cistern prior to deployment.

Initial planning calls have used these virtual systems to communicate design and installation intent, and to solicit feedback. It is important to note that in this phase, the complexity of the design is minimal and product complexity should be kept as low as possible with the foreknowledge of more complex prototyping and deployment environments. 
This project is currently in the prototyping phase (Figure 1,3), moving into the field testing phase (Figure 1, 4). Design iteration will now occur through field prototyping (Figure 1, B), with a heavy emphasis on feedback between the design team and the collaborator team. A field testing installation of 3 CISTERN sensors, communicating via radio with satellite gateways, were installed in August 2019. Design engineers and collaborator staff will install these initial sensors together. The field prototyping process will begin as feedback from sensor data, and local collaborators is moderated by the design team. A co-design process will be undertaken to adapt an existing dashboard framework to the use case.

\section{Discussion}

Our proposed design approach to support service providers in low-income settings builds on, and contrasts against, other established design methodologies.

The design approach proposed in this paper builds on Lean Design, including a particular focus on feedback loops between different types of designers and their customers, and iterative techniques [35]. Lean Design is widely used to improve manufacturing operations and product quality, rather than being applied to original product design. Lean Design is focused on optimizing products while minimizing wasteful operations. Lean approaches may not be suitable to our context since it traditionally relies on iteration to converge to a solution, without the added distance design benefits of product simulation [36]. Others have pointed to geographical distance as a serious limitation to the Lean Design approach [37], calling into question the applicability of this process in the context of global development.

Set-based concurrent engineering (SBCE) is emerging as a design-focused alternative to Lean Design. SBCE frames design solutions as optimization problems that need to account for overlapping sets of feasibility within a design space, attempting to narrow in on a final design early in the design process [38]. However, from its very conception, SBCE has been contingent on teams in firms that develop "deep technical expertise in both its engineering and management ranks." [39]. The SBCE approach is again a response to managing the complexity of large machine systems, such as automobiles or aircraft. Our experience indicates that the complexities of deployed products themselves are dwarfed by the complexities of the deployment context and that field deployment is a necessary step towards design optimization.

Design thinking theory is defined by a focus on value creation stemming from a deep understanding of the intended product user. A heavy focus is placed on empathy and iteration. Design thinking has gained traction as a more participatory process by allowing non-designers to play a designer role, as has the idea of applying design theory to management functions [40]. Recently, the definition of design thinking appears to have shifted in this direction, describing the use of design-like skillsets in non-designer professions [41]. In the international development context, design thinking has been championed by IDEO (Palo Alto, CA, USA) and has become difficult to discern from the human-centered design movement. Like SBCE, design thinking in this context attempts to eschew traditional, linear design processes in favor of overlapping design spaces [42]. Design thinking's focus on an empathetic relationships between a product designer and an end-user are valuable but are less applicable to projects co-designed by product designers and service providers than the design theory presented here.

The case studies presented demonstrate where remote design has been successfully applied to help close some of the contextual barriers that often cause products to fail [20]. Using advanced CAD tools to integrate collaborator feedback before deploying the first prototypes to the field for testing can increase the odds of a successful and fruitful first deployment. During the planning phase of a project, a virtual environment representing a minimally complex deployment environment is used to decrease the number of field prototyping iterations required for a successful product roll-out. This approach is similar to virtual design theory [43] but differs in a significant way: where virtual design is a response to the requirements 
of large, multi-disciplinary design teams, design for service delivery attempts to decrease the complexity of the design process by clearly defining the roles of disciplines involved, especially for small teams spread across large distances. Where virtual design is a response to "large, complex project[s]" [44] or for simulating complex mechanical behavior prior to manufacturing [45], our design approach is a response to complex deployment environments.

\section{Conclusions and Future Work}

Recent design literature has laudably called for engineers' participation in efforts to address global poverty, access to basic resources, and public health concerns. The same literature points to an increased interest in the engineering and design communities in doing high-impact work. As a part of developing a coherent theory of global engineering, distinct from project-based models or consumer-focused product design, this paper contributes to design approaches supporting service delivery.

Service design thinking is a relatively recent theory that attempts to pivot market logic away from the exchange of goods towards a focus on service provision [46]. As such, this reframing is highly compatible with our design approach. This design theory is co-evolving with the emerging field of "service science", which attempts to reframe markets in terms of "service systems" through which goods are a service distribution mechanism rather than the main driver of exchange [47]. Service design thinking appears to currently be converging with the more mature field of design thinking [48] and is too young to evaluate as effective or ineffective in our context.

At a time when engineering students and professionals are eager to contribute to poverty alleviation and public health programs, design approaches and products that support the professionalized delivery of critical services may be an increasingly valuable contribution.

Author Contributions: Conceptualization, T.S., C.M., and E.T.; methodology, T.S., C.M., and E.T.; software, T.S.; writing-original draft preparation, T.S.; writing—review and editing, C.M., E.T.; visualization, T.S.; supervision, E.T.; project administration, E.T.; funding acquisition, E.T.

Funding: Funding for this work was provided in part by the Autodesk Foundation.

Conflicts of Interest: Authors T.S. and E.T. are employed at the University of Colorado Boulder. All authors are also employed by SweetSense Inc., the social technology enterprise commercializing the sensors described in this paper. The Autodesk Foundation had no role in the design of the work described; in the collection, analyses, or interpretation of data; in the writing of the manuscript, or in the decision to publish the results.

\section{References}

1. Lucena, J.; Schneider, J. Engineers, development, and engineering education: From national to sustainable community development. Eur. J. Eng. Educ. 2008, 3797. [CrossRef]

2. Mitcham, C.; Munoz, D. Humanitarian Engineering. Synth. Lect. Eng. Technol. Soc. 2010. [CrossRef]

3. Jagtap, S. Design and poverty: A review of contexts, roles of poor people, and methods. Res. Eng. Des. 2019, 30, 41-62. [CrossRef]

4. Chua, C.K.; Leong, K.F.; Lim, C.S. Rapid Prototyping: Principles and Applications, 3rd ed.; World Scientific: Singapore, 2010.

5. Wasley, N.S.; Lewis, P.K.; Mattson, C.A.; Ottosson, H.J. Experimenting with concepts from modular product design and multi-objective optimization to benefit people living in poverty. Dev. Eng. 2016, 2, 29-37. [CrossRef]

6. IDEO. The Field Guide to Human-Centered Design; IDEO: Palo Alto, CA, USA, 2015.

7. Progress on Household Drinking Water, Sanitation and Hygiene 2000-2017; WHO/UNICEF Joint Monitoring Programme for Water Supply and Sanitation (JMP); WHO: Geneva, Switzerland, 2019; p. 140.

8. Tracking SDG7: The Energy Progress Report 2019; The World Bank: Washington, DC, USA, 2019.

9. Yunthas, K.; Thomas, E.A. Performance Over Promises. In Broken Pumps and Promises: Incentivizing Impact in Environmental Health; Thomas, E.A., Ed.; Springer: Berlin/Heidelberg, Germany, 2016; Chapter 2, pp. 5-17. 
10. Nagel, C.L.; Kirby, M.A.; Zambrano, L.D.; Rosa, G.; Barstow, C.K.; Thomas, E.A.; Clasen, T.F. Study design of a cluster-randomized controlled trial to evaluate a large-scale distribution of cook stoves and water filters in Western Province, Rwanda. Contemp. Clin. Trials Commun. 2016. [CrossRef]

11. Sinha, A.; Nagel, C.L.; Thomas, E.; Schmidt, W.P.; Torondel, B.; Boisson, S.; Clasen, T.F. Assessing latrine use in rural India: A cross-sectional study comparing reported use and passive latrine use monitors. Am. J. Trop. Med. Hyg. 2016. [CrossRef]

12. Thomas, E.A.; Barstow, C.K.; Rosa, G.; Majorin, F.; Clasen, T. Use of remotely reporting electronic sensors for assessing use of water filters and cookstoves in Rwanda. Environ. Sci. Technol. 2013. [CrossRef]

13. Turman-Bryant, N.; Thomas, E.A.; Sharpe, T.J.; Nagel, C.L.; Stover, L. Toilet Alarms: A Novel Application of Latrine Sensors and Machine Learning for Optimizing Sanitation Services in Informal Settlements. J. Dev. Eng. 2019, In press.

14. Thomas, E.A.; Needoba, J.; Kaberia, D.; Butterworth, J.; Adams, E.C.; Oduor, P.; Macharia, D.; Mitheu, F.; Mugo, R.; Nagel, C. Quantifying increased groundwater demand from prolonged drought in the East African Rift Valley. Sci. Total Environ. 2019, 666, 1265-1272. [CrossRef]

15. Thomas, E. Toward a new field of global engineering. Sustainability 2019, 11, 3789. [CrossRef]

16. Donaldson, K.M. Product design in less industrialized economies: Constraints and opportunities in Kenya. Res. Eng. Des. 2006, 17, 135-155. [CrossRef]

17. Chandra, M.; Neelankavil, J.P. Product development and innovation for developing countries: Potential and challenges. J. Manag. Dev. 2008, 27, 1017-1025. [CrossRef]

18. Best, A.; Holmes, B. Towards Better Models and Methods. Evid. Policy 2010, 6, 145-159. [CrossRef]

19. Wynn, D.C.; Eckert, C.M. Perspectives on iteration in design and development. Res. Eng. Des. 2017. [CrossRef]

20. Donaldson, K. The Future of Design for Development: Three Questions. Inf. Technol. Int. Dev. 2009, 5, 97-100.

21. Mattson, C.A.; Wood, A.E. Nine Principles for Design for the Developing World as Derived From the Engineering Literature. J. Mech. Des. 2014, 136, 121403. [CrossRef]

22. Wood, A.E.; Mattson, C.A. Design for the Developing World: Common Pitfalls and How to Avoid Them. J. Mech. Des. 2016, 138, 031101. [CrossRef]

23. Thomas, E.; Alberto Andrés, L.; Borja-Vega, C.; Sturzenegger, G. Innovations in WASH Impact Measures Water and Sanitation Measurement Technologies and Practices to Inform the Sustainable Development Goals Directions in Development Infrastructure; World Bank Group: Washington, DC, USA, 2018.

24. Chou, S.; Austin-Breneman, J. Prototyping methods and constraints for small-to-medium sized enterprises in East Africa. Dev. Eng. 2018, 3, 117-124. [CrossRef]

25. Chulvi, V.; Mulet, E.; Felip, F.; García-García, C. The effect of information and communication technologies on creativity in collaborative design. Res. Eng. Des. 2017, 28, 7-23. [CrossRef]

26. Kozemjakin da Silva, M.; Remy, S.; Reyes, T. On providing design process information to the environmental expert. Res. Eng. Des. 2015, 26, 327-336. [CrossRef]

27. Sole, D.; Edmondson, A. Situated Knowledge and Learning in Dispersed Teams. Br. J. Manag. 2003, 13, S17-S34. [CrossRef]

28. Whittle, D.B. How Feedback Loops Can Improve Aid and Governance. In Broken Pumps and Promises: Incentivizing Impact in Environmental Health; Thomas, E.A., Ed.; Springer International Publishing: Cham, Switzerland, 2016; pp. 31-45._4. [CrossRef]

29. Thomson, P.; Koehler, J. Performance-oriented Monitoring for the Water SDG-Challenges, Tensions and Opportunities. Aquat. Procedia 2016, 6, 87-95. [CrossRef]

30. Allen, J.D.; Mattson, C.A.; Thacker, K.S.; Ferguson, S.M. Design for excess capability to handle uncertain product requirements in a developing world setting. Res. Eng. Des. 2017, 28, 511-527. [CrossRef]

31. Clasen, T.; Fabini, D.; Boisson, S.; Taneja, J.; Song, J.; Aichinger, E.; Bui, A.; Dadashi, S.; Schmidt, W.P.; Burt, Z.; et al. Making sanitation count: Developing and testing a device for assessing latrine use in low-income settings. Environ. Sci. Technol. 2012. [CrossRef] [PubMed] 
32. Turman-Bryant, N.; Nagel, C.; Stover, L.; Muragijimana, C.; Thomas, E. Improved Drought Resilience Through Continuous Water Service Monitoring and Specialized Institutions-A Longitudinal Analysis of Water Service Delivery Across Motorized Boreholes in Northern Kenya. Sustainability 2019, 11, 3046. [CrossRef]

33. Kingdom, B.; Liemberger, R.; Marin, P. The Challenge of Reducing Non-Revenue Water (NRW) in Developing Countries How the Private Sector Can Help: A Look at Performance-Based Service Contracting; Water Supply and Sanitation Sector Board Discussion Paper Series; Technical Report 8; The World Bank: Washington, DC, USA, 2006.

34. Colchester, F.E.; Marais, H.G.; Thomson, P.; Hope, R.; Clifton, D.A. Accidental infrastructure for groundwater monitoring in Africa. Environ. Model. Softw. 2017, 91, 241-250. [CrossRef]

35. Bicheno, J.; Holweg, M. The Lean Toolbox; PICSIE Books; Buckingham Lean Enterprise Unit, University of Buckingham: Buckingham, UK, 2016; p. 290.

36. Marvel, J.H.; Standridge, C.R. A simulation-enhanced lean design process. J. Ind. Eng. Manag. 2009 , 2, 90-113. [CrossRef]

37. Cusumano, M.A. The Limits of Lean. Sloan Manag. Rev. 1994, 35, 4.

38. Raudberget, D. Enabling set-based concurrent engineering in traditional product development. In Proceedings of the 18th International Conference on Engineering Design, Copenhagen, Denmark, 15-19 August 2011; Volume 1, pp. $45-56$.

39. Sobek, D.K.; Allen, I.I.; Jeffrey, C.W. Toyota's Principles of Set-Based Concurrent Engineering. Sloan Manag. Rev. $1999,40,67$.

40. Dunne, D.; Martin, R. Design thinking and how it will change management education: An interview and discussion. Acad. Manag. Learn. Educ. 2006, 5, 512-523. [CrossRef]

41. Pavie, X.; Carthy, D. Leveraging Uncertainty: A Practical Approach to the Integration of Responsible Innovation through Design Thinking. Procedia Soc. Behav. Sci. 2015, 213, 1040-1049. [CrossRef]

42. Pieniazek, M. Design thinking for social innovation. In Social Entrepreneurship: A Skills Approach, 2nd ed.; Policy Press, University of Bristol: Bristol, UK, 2016; pp. 65-70. [CrossRef]

43. Kunz, J.C.; Christiansen, T.R.; Cohen, G.P.; Jin, Y.; Levitt, R.E. The virtual design team. Commun. ACM 1998, 41, 84-91. [CrossRef]

44. Jin, Y.; Levitt, R.E. The virtual design team: A computational model of project organizations. Comput. Math. Organ. Theory 1996, 2, 171-195. [CrossRef]

45. Altintas, Y.; Cao, Y. Virtual design and optimization of machine tool spindles. CIRP Ann. Manuf. Technol. 2005, 54, 379-382. [CrossRef]

46. Vargo, S.L.; Lusch, R.F. Evolving to a New Dominant Logic for Marketing. J. Mark. 2004, 68, 1-17. [CrossRef]

47. Vargo, S.L.; Lusch, R.F. Service-dominant logic: Continuing the evolution. J. Acad. Mark. Sci. 2008, 36, 1-10. [CrossRef]

48. Gobble, M.M. Design Thinking, Research-Technology Management. Res.-Technol. Manag. $2014,57,59-62$. [CrossRef]

(C) 2019 by the authors. Licensee MDPI, Basel, Switzerland. This article is an open access article distributed under the terms and conditions of the Creative Commons Attribution (CC BY) license (http:/ / creativecommons.org/licenses/by/4.0/). 